\title{
Oral corticosteroid use and the risk of acute myocardial infarction in chronic obstructive pulmonary disease
}

\author{
Laetitia Huiart $M D^{1,2}$, Pierre Ernst $M D^{1}$, Xavier Ranouil MD³ , Samy Suissa PhD
}

\begin{abstract}
L Huiart, P Ernst, X Ranouil, S Suissa. Oral corticosteroid use and the risk of acute myocardial infarction in chronic obstructive pulmonary disease. Can Respir J 2006;13(3):134-138.
\end{abstract}

BACKGROUND: Given the limited efficacy of oral corticosteroids in treating chronic obstructive pulmonary disease (COPD), the possible cardiac side effects of oral corticosteroids are of particular concern in an elderly population. The impact of the use of oral corticosteroids on the risk of acute myocardial infarction (AMI) in a cohort of patients with COPD was studied.

METHODS: The Saskatchewan health services databases were used to form a population-based cohort of 5648 patients aged 55 years or older who received a first treatment for COPD between 1990 and 1997. A nested case-control analysis was conducted: 371 cases presenting with a first myocardial infarction were matched with 1864 controls according to the length of follow-up, the date of cohort entry and age. Conditional logistic regression was used to adjust for sex, severity of COPD, systemic hypertension, diabetes and prior cardiovascular disease.

RESULTS: Only the current use of corticosteroids was associated with an increased risk of AMI (adjusted RR=2.01 [95\% CI 1.13 to 3.58]), particularly when the current dose was larger than $25 \mathrm{mg} /$ day of prednisone or the equivalent (adjusted RR=3.22 [95\% CI 1.42 to 7.34$]$ ). This observed increase in risk rapidly returned to baseline after the cessation of the medication, suggesting that the use of such high doses reflected the treatment of acute exacerbations of the disease. CONCLUSIONS: An association was found between the current use of oral corticosteroids and the occurrence of an AMI, suggesting that acute exacerbations of COPD are associated with an increased risk of acute coronary syndromes.

Key Words: Adverse effects; Cohort studies; COPD; Glucocorticoids; Myocardial infarction

\section{Le recours à la corticothérapie orale et le risque d'infarctus aigu du myocarde en cas de maladie pulmonaire obstructive chronique}

HISTORIQUE : Étant donné l'efficacité limitée de la corticothérapie orale pour traiter la maladie pulmonaire obstructive chronique (MPOC), les effets secondaires cardiovasculaires éventuels de la corticothérapie orale deviennent particulièrement préoccupants au sein de la population âgée. Les répercussions de leur usage sur le risque d'infarctus aigu du myocarde (IAM) ont été étudiées au sein d'une cohorte de patients atteints de MPOC.

MÉTHODOLOGIE : Les bases de données des services de la santé de la Saskatchewan ont été utilisées pour former une cohorte représentative de 5648 patients de 55 ans ou plus qui avaient reçu un premier traitement contre la MPOC entre 1990 et 1997. Une analyse cas-témoins à plusieurs critères de classification a été menée : 371 cas présentant un premier infarctus du myocarde ont été jumelés à 1864 témoins d'après la durée de suivi, la date d'arrivée dans la cohorte et l'âge. Une régression logistique conditionnelle a été utilisée pour effectuer les rajustements reliés au sexe, à la gravité de la MPOC, à l'hypertension systémique, au diabète et à une maladie cardiovasculaire préalable.

RÉSULTATS : Seul le recours courant à la corticothérapie s'associait à un risque accru d'IAM (RR rajusté=2,01 [95 \% IC 1,13 à 3,58]), surtout lorsque la dose était supérieure à $25 \mathrm{mg} / \mathrm{jour}$ de prednisone ou d'un équivalent (RR rajusté=3,22 [95 \% IC 1,42 à 7,34]). Cette augmentation observée du risque revenait rapidement aux valeurs de base après l'abandon du médicament, ce qui indique que le recours à des doses si élevées reflétait le traitement d'exacerbations aiguës de la maladie.

CONCLUSIONS : On a constaté une association entre le recours courant à la corticothérapie orale et l'occurrence d'IAM, ce qui laisse supposer que des exacerbations aiguës de la MPOC s'associent à une augmentation du risque de syndromes coronariens aigus.
Chronic obstructive pulmonary disease (COPD) is among the five most prevalent diseases and is a leading cause of death worldwide (1). The pharmacological management of COPD includes the use of bronchodilators and antibiotics during exacerbations of the disease, as well as oxygen therapy when necessary (2). Oral and inhaled corticosteroids are also commonly used in the management of patients with COPD (3). Oral corticosteroids have been shown to have limited benefit in stable, chronic COPD patients (4), despite a significant benefit in the management of acute exacerbations (5).
The beneficial effect of corticosteroids is clear only in the short term for the treatment of an exacerbation and may be offset by an increase in the risk of adverse events, especially with more prolonged use (6). In particular, corticosteroids are known to promote hypertension, dyslipidemia and glucose intolerance, which constitute well-recognized risk factors for cardiovascular disease $(7,8)$. The impact of corticosteroids on the cardiovascular system has been well documented for patients undergoing solid organ transplantations (9), as well as for patients with lupus (10) and rheumatoid arthritis (11).

${ }^{1}$ Division of Clinical Epidemiology, Royal Victoria Hospital and Department of Epidemiology and Biostatistics, McGill University, Montréal, Québec; ${ }^{2}$ Laboratoire de Santé Publique EA 3279, Université de la Méditerranée, Marseille, France; ${ }^{3}$ Institut Cardiologique de Montréal, Université de Montréal, Montréal, Québec

Correspondence: Dr Samy Suissa, Division of Clinical Epidemiology, Royal Victoria Hospital, 687 Pine Avenue West, Ross 4.29, Montréal,

Québec H3A 1A1. Telephone 514-843-1564, fax 514-843-1493, e-mail samy.suissa@clinepi.mcgill.ca 
However, the incidence and severity of cardiovascular adverse events associated with the use of oral corticosteroids have not been documented in the context of COPD. This is of particular concern because this population is usually older, less active and has a more important smoking history than the general population. In addition, chronic bronchitis (12) and lung function (13) have been identified as independent predictors of the occurrence of coronary artery disease. On the other hand, ischemic heart disease, once present, is an important comorbid factor that predicts all-cause mortality in patients with COPD (14). We therefore investigated the impact of oral corticosteroids on the risk of myocardial infarction among a populationbased sample of patients with COPD.

\section{Source of data and population}

\section{METHODS}

The Health Insurance Databases of Saskatchewan were the primary source of data. These databases include all residents eligible for health coverage (approximately 91\% of the population) (15). A population-based cohort of new cases of COPD based entirely on prescriptions dispensed was defined. To enter the cohort, a minimum of three prescriptions of inhaled or oral beta-2-agonist, xanthine or ipratropium must have been received on two different dates during any 12 -month period. The entry date was the time of the third prescription for a COPD medication between 1990 and 1997. Subjects were followed until the first acute myocardial infarction (AMI), the end of 1999 or the end of coverage, whichever came first. To include only newly diagnosed cases of COPD, and to distinguish between asthma and COPD, patients had to be 55 years of age or older on the day of their first COPD medication prescription, and patients who had received any beta-2-agonist, xanthine, antiasthma drug (eg, cromolyn, nedocromil or ketotifen), or nasal or inhaled corticosteroids in the prior five years were excluded. However, if a patient was labelled as having asthma, rather than COPD, during a hospitalization after cohort entry, then they were not excluded. Subjects were excluded if they had an AMI in the five-year period before cohort entry.

The outcome of interest was the first AMI, identified by using discharge diagnoses from hospital or the underlying cause of death (International Classification of Diseases, Ninth Revision [ICD-9] code 410 [16]). The recording of AMI in the Saskatchewan hospital services database has been previously studied and compared with medical charts; diagnostic agreement with the hospital separation database was as high as $97 \%(17)$.

Because exposure to medications varied over time in the cohort, a nested case-control design was used within the cohort to provide valid estimates of rate ratios with little loss in power (18). Each case of AMI was matched to all possible controls within the cohort based on age and time of cohort entry; matching on cohort entry was performed to control for secular trends and disease duration. Controls had to be at risk at the time of the case subject's AMI (index date); that is, they had to be alive, living in Saskatchewan and not have had an AMI on this date.

The effects of oral corticosteroids were investigated according to the strength, quantity and date dispensed. All oral corticosteroid prescriptions identified from the drug prescription database were converted to prednisone-equivalent units by using the standard relative glucocorticoid potencies (19). Exposure to oral corticosteroids was examined in the 12-month period before an AMI and the corresponding period for the controls. These 12 months of exposure were further divided into either current exposure (ie, subjects had been dispensed oral corticosteroids within 14 days before the index date) or past exposure (ie, subjects had received oral corticosteroids in the past 12 months but not within 14 days before the index date). The duration between the most recent prescription of the drug and the index date defined the recency of use. Because durations of prescriptions were not recorded in the database, a mean duration of 14 days was used for oral corticosteroid prescriptions; this decision was based on clinical recommendations and durations observed in the database of another Canadian province (20).

Covariates noted included age, sex, systemic hypertension, diabetes, hyperlipidemia, ischemic heart disease and severity of COPD. Systemic hypertension, diabetes and hyperlipidemia were identified by the drugs dispensed in the 12 months before cohort entry. Heart failure and pulmonary heart disease were identified from hospital discharge diagnoses anytime before cohort entry (ICD-9 codes 428.x and 416.x, respectively). Ischemic heart disease was considered present if subjects had been prescribed nitrates in the 12 months before cohort entry or had a discharge diagnosis suggesting ischemic heart disease (but not AMI because these subjects had been excluded) any time before cohort entry (ICD-9 codes 411.0 to 414.9, inclusively).

The severity of the respiratory disease was controlled for by matching of age and duration of disease, and by adjusting for COPD treatment as follows: adjusting for the number of prescriptions of inhaled beta-2-agonist, xanthine or ipratropium in the 12 months before the index date; and adjusting for the dispensing or nondispensing of inhaled corticosteroids. The number of exacerbations of COPD during follow-up was defined as the number of hospitalizations with COPD as the primary discharge diagnosis, and the number of times when, within a seven-day period, antibiotics and oral corticosteroids were simultaneously prescribed.

The effects of acetylsalicylic acid and other nonsteroidal antiinflammatory agents were investigated. It should be noted, however, that this category of medication is available over-the-counter and, thus, would not be recorded in the databases.

Techniques for matched case-control studies were used to take into account the individual matching in the analyses. To account for the variable number of controls per case in each risk set, descriptive statistics were weighted by the inverse of the number of controls in each matched set; this is equivalent to standardizing the number of controls to one control per case. A multivariate conditional logistic regression model was used to calculate odds ratios and $95 \%$ confidence intervals. Odds ratios were used as estimates of rate ratios. The reference category was the absence of oral corticosteroid use in the 12-month period before the index date. The model was adjusted for all known confounders and covariates that were found to modify the effect. The assessment of COPD severity providing the best fit was based on the number of canisters or nebulized prescriptions of bronchodilators (categorized as zero, one to 12 or more than 12 prescriptions in the prior 12 months), and whether inhaled corticosteroids were dispensed in the prior 12 months. The number of COPD exacerbations was not adjusted for because oral corticosteroid exposure was part of the definition of this variable. Because only outpatient prescriptions are available in the Saskatchewan databases, subjects were excluded if they had been hospitalized for more than 30 days in the prior three months or more than 90 days in the prior 12 months. Whether the associations examined were influenced by being hospitalized in the prior three months for whatever cause was also examined. SAS software (version 8.02, SAS Institute, USA) was used for statistical analyses.

Variables in the final model examining the relationship between AMI and the use of oral corticosteroids included sex, markers of severity of COPD, hospitalization in the prior three months, hypertension, diabetes, ischemic heart disease and heart 
TABLE 1

Characteristics of the study population

\begin{tabular}{|c|c|c|}
\hline Characteristics & $\begin{array}{l}\text { Case subjects } \\
\quad(n=371)\end{array}$ & $\begin{array}{l}\text { Controls* } \\
(n=1864)\end{array}$ \\
\hline Mean age, years \pm SD & $77.7 \pm 8.6$ & $77.7 \pm 3.8$ \\
\hline Men, n (\%) & $243(65.5)$ & $949(50.9)$ \\
\hline Mean duration of follow-up, years $\pm S D$ & $2.5 \pm 2.2$ & $2.6 \pm 1.0$ \\
\hline \multicolumn{3}{|l|}{ Medical characteristics at cohort entry, $\mathrm{n}(\%)$} \\
\hline Diabetes & $60(16.2)$ & $128(6.9)$ \\
\hline Systemic hypertension & $244(65.8)$ & $940(50.4)$ \\
\hline Dyslipidemia & $16(4.3)$ & $59(3.2)$ \\
\hline Ischemic heart disease & $155(41.8)$ & $332(17.8)$ \\
\hline Heart failure & $104(28.0)$ & $252(13.5)$ \\
\hline \multicolumn{3}{|l|}{ COPD cotherapy prescriptions ${ }^{\dagger}$} \\
\hline Beta-2-agonists, mean \pm SD & $2.2 \pm 3.6$ & $2.0 \pm 1.5$ \\
\hline Inhaled ipratropium, mean \pm SD & $1.5 \pm 3.1$ & $1.3 \pm 1.4$ \\
\hline Nebulized beta-2-agonists, mean \pm SD & $1.4 \pm 4.1$ & $1.2 \pm 2.1$ \\
\hline Theophylline, mean \pm SD & $0.9 \pm 2.7$ & $0.9 \pm 1.2$ \\
\hline Inhaled corticosteroids, n (\%) & $157(42.3)$ & $864(46.4)$ \\
\hline \multicolumn{3}{|l|}{$\begin{array}{l}\text { Number of COPD exacerbations } \\
\text { before index date, } \mathrm{n}(\%)^{\ddagger}\end{array}$} \\
\hline 0 & $248(66.8)$ & $1320(70.8)$ \\
\hline 1 to 2 & $84(22.6)$ & $411(22.0)$ \\
\hline 3 or more & $39(10.5)$ & $133(7.1)$ \\
\hline $\begin{array}{l}\text { Hospitalization (any cause) in } \\
\text { the past } 3 \text { months, } n(\%)\end{array}$ & $110(29.6)$ & $181(9.7)$ \\
\hline Acetylsalicylic acid, n (\%) & $38(10.2)$ & $116(6.2)$ \\
\hline $\begin{array}{l}\text { Other nonsteroidal anti-inflammatory } \\
\text { agent, } n(\%)\end{array}$ & $91(24.5)$ & $411(22.0)$ \\
\hline
\end{tabular}

${ }^{*} T o$ account for the variable number of controls in each matched set, all means $\pm S D$ and percentages are weighted by the inverse of the number of controls in each set; 'Dispensed in the 12 months before the index date; ¥Exacerbations are defined as the number of hospitalizations with chronic obstructive pulmonary disease (COPD) as the primary discharge diagnosis, and the number of concurrent prescriptions (within a seven-day period) of antibiotics and corticosteroids

failure. The adjustment for treated dyslipidemia, the use of acetylsalicylic acid and the use of other anti-inflammatory agents did not affect the association between oral corticosteroids and AMI; therefore, these variables were not considered to be confounders and are not included in the final model.

\section{RESULTS}

Among the cohort of 5648 subjects newly treated for COPD, 569 subjects were excluded due to a previous hospitalization for AMI in their medical records. Among the 392 case subjects who had an AMI, six case subjects were excluded because they had less than five years of health coverage before cohort entry. Fifteen other subjects were excluded who had durations of hospitalization longer than 30 days within the three months before the index date or longer than 90 days within the 12 months before the index date. The same selection procedure was applied to controls. The remaining 371 case subjects (256 having a nonfatal AMI and 115 having a fatal AMI) were matched with 1864 controls (one to 13 controls per case).

The mean age of the study population was 77.7 years (range 57 to 98 years). Indicators of COPD severity and medical characteristics at the time of cohort entry are described in Table 1. Compared with controls, more case subjects experiencing an AMI were men, and more had comorbid or associated conditions such as diabetes, hypertension, dyslipidemia, ischemic heart disease and heart failure. COPD also seemed more severe in case subjects, as shown by the more frequent prescribing of the various bronchodilators, although not inhaled corticosteroids. Patients experiencing an AMI had also been hospitalized substantially more frequently in the three months before the event than the controls who did not experience this event.

In the previous year, oral corticosteroids had been dispensed to $29.4 \%$ of case subjects $(n=109)$ and $25.4 \%$ of controls $(n=486)$ (Table 2). Any dispensing of oral corticosteroids in the prior 12 months was associated with a small increase in the risk of an AMI, which was of borderline statistical significance after adjustment ( $R R=1.35$ [95\% CI 1.00 to 1.81]). Current exposure was associated with an increase in the risk of $A M I(R R=2.01$ [95\% CI 1.13 to 3.58]), whereas the risk was no longer significantly increased if current exposure was excluded $(R R=1.24$ [95\% CI 0.90 to 1.70]). For subjects currently exposed, most of the risk was associated with a current prescription of daily doses of $25 \mathrm{mg}$ or more of prednisone or the equivalent (adjusted RR of 3.22 [95\% CI 1.42 to 7.34 ] versus an adjusted RR of 1.32 [95\% CI 0.58 to 3.02] for those subjects dispensed lesser doses). The increase in risk observed among subjects who were currently exposed returned to baseline rapidly after the cessation of the medication, such that an association with AMI was no longer present for a prescription dispensed 15 to 30 days, or more remotely, before the event (Table 3).

\section{DISCUSSION}

Among patients with COPD, coronary artery disease is recognized as a frequent cause of morbidity and mortality $(14,21,22)$. This is hardly surprising given the common risk factors, such as age and smoking, for these two conditions. It

TABLE 2

Matched crude and adjusted rate ratios for acute myocardial infarction in relation to the use of oral corticosteroids during the one-year period before the index date*

\begin{tabular}{|c|c|c|c|c|}
\hline $\begin{array}{l}\text { Use of oral } \\
\text { corticosteroids }\end{array}$ & $\begin{array}{l}\text { Case subjects, } n(\%) \\
\qquad(n=371)\end{array}$ & $\begin{array}{l}\text { Controls, } n(\%) \\
\quad(n=1864)\end{array}$ & $\begin{array}{l}\text { Crude RR } \\
(95 \% \mathrm{Cl})\end{array}$ & $\begin{array}{c}\text { Adjusted RR } \\
(95 \% \mathrm{Cl})^{\dagger}\end{array}$ \\
\hline \multicolumn{5}{|c|}{ Exposure in the past 12 months } \\
\hline None & $262(70.6)$ & $1378(73.9)$ & \multicolumn{2}{|c|}{1 (reference group) } \\
\hline Any use & $109(29.4)$ & $486(26.1)$ & $1.27(0.98-1.65)$ & $1.35(1.00-1.81)$ \\
\hline Current exposure $\ddagger$ & $22(5.9)$ & $49(2.6)$ & $2.41(1.43-4.06)$ & $2.01(1.13-3.58)$ \\
\hline Past exposure $\S$ & $87(23.5)$ & $437(23.4)$ & $1.12(0.84-1.49)$ & $1.24(0.90-1.70)$ \\
\hline
\end{tabular}

${ }^{*}$ The index date for case subjects and matched controls was the date of the case subject's acute myocardial infarction; ${ }^{2} R R$ s were adjusted for subject age and duration of disease (by study design), and for sex, number of prescriptions of bronchodilators in the past 12 months (none, one to 12 or more than 12), inhaled corticosteroid use, hospitalization in the past three months, diabetes, systemic hypertension, ischemic heart disease and heart failure; $¥$ To be currently exposed, subjects had to have received a prescription for oral corticosteroids within 14 days before the index date; §Past exposure was defined as being exposed in the past year, but not currently exposed 
Oral corticosteroids and acute myocardial infarction

TABLE 3

Matched crude and adjusted rate ratios for acute myocardial infarction in relation to the recency of oral corticosteroid use

\begin{tabular}{lcccc}
\hline Recency of oral corticosteroid use & $\begin{array}{c}\text { Case subjects, } \mathbf{n}(\%) \\
(\mathbf{n}=\mathbf{3 7 1})\end{array}$ & $\begin{array}{c}\text { Controls, } \mathbf{n}(\%) \\
(\mathbf{n = 1 8 6 4 )}\end{array}$ & Crude RR (95\% Cl) & Adjusted RR (95\% Cl) \\
\hline Within 14 days before index date & $22(5.9)$ & $49(2.6)$ & $2.41(1.43-4.10)$ & $2.01(1.12-3.58)$ \\
15 to 30 days before index date & $13(3.5)$ & $46(2.5)$ & $1.51(0.80-2.82)$ & $1.14(0.57-2.26)$ \\
31 to 60 days before index date & $11(3.0)$ & $38(2.0)$ & $1.53(0.77-3.04)$ & $1.24(0.57-2.69)$ \\
More than 60 days before index date & $63(17.0)$ & $353(18.9)$ & $1.00(0.73-1.38)$ & $1.26(0.88-1.81)$ \\
\hline
\end{tabular}

${ }^{*}$ Based on date of last prescription; ${ }^{\dagger} R R s$ were adjusted for subject age and duration of chronic obstructive pulmonary disease (by study design), and for sex, number of prescriptions of bronchodilators in the past 12 months (none, one to 12 or more than 12), inhaled corticosteroid use, hospitalization in the past three months, diabetes, systemic hypertension, ischemic heart disease and heart failure

has also been recognized that markers of cardiac involvement can predict mortality among patients with COPD hospitalized for exacerbations (23).

In the present study, we found an association between the dispensing of large doses of oral corticosteroids among a cohort of patients with COPD and the occurrence of an AMI. This association was only present with the current use of oral corticosteroids, with the risk rapidly returning to baseline after cessation of use. This strongly suggests that the observed association is actually due to an increased risk of AMI with acute exacerbations of COPD, which are treated with large doses of oral corticosteroids, rather than due to any direct effect of oral corticosteroids on the risk of AMI itself.

Our findings have a possible alternative explanation. In the few days preceding a cardiovascular event, some patients may present with cardiovascular symptoms that may be misdiagnosed as a worsening of their respiratory condition, for which corticosteroids are prescribed. However, this would be less likely to explain the decrease in risk after treatment cessation.

We used a population-based cohort compiled from administrative health services databases. This source of data provides two major advantages. First, these databases cover essentially an entire population and, therefore, their use limits selection bias. Second, exposure to corticosteroids is measured with high accuracy because they are available by prescription only, and because the Saskatchewan Prescription Drug Plan is the primary insurer of Saskatchewan formulary benefits in the province and requires that all claims be processed through the on-line drug plan system. However, the dispensing of a prescription does not ensure that the subject has ingested the drug.

The database that we used does not provide information on some important clinical data and confounders. Our study population was defined by drugs dispensed, and the distinction between COPD and asthma is difficult in this context. Because the incidence of asthma in adults older than 50 years of age is very low (24), we limited misdiagnosis by including only subjects who had a newly treated respiratory disease after 55 years of age and who required more than occasional treatment. We

\section{REFERENCES}

1. World Health Organization. Life in the 21st Century: A Vision for All. Geneva: WHO, 1998.

2. American Thoracic Society. Standards for the diagnosis and care of patients with chronic obstructive pulmonary disease. Am J Respir Crit Care Med 1995;152:S77-121.

3. Rudolf M. The reality of drug use in COPD: The European perspective. Chest 2000;117(Suppl 2):29S-32S.

4. Callahan CM, Dittus RS, Katz BP. Oral corticosteroid therapy for patients with stable chronic obstructive pulmonary disease.

Ann Intern Med 1991;114:216-23.

5. Wood-Baker R, Walters EH, Gibson P. Oral corticosteroids for acute also excluded prevalent asthmatic patients by excluding subjects who had received treatment for asthma in the five years before cohort entry. In the present study, inclusion of asthma patients would have likely underestimated the increase in risk associated with oral corticosteroids because the risk of cardiovascular events may be lower for these patients. Administrative databases do not collect information on smoking, an important risk factor for AMI. To be a confounder in our study, smoking would also have to be associated with the use of oral corticosteroids. To assess this association, we used data from the Canadian National Population Health Survey (1996-1997) (25). These data indicate that among the subjects who had been diagnosed with chronic bronchitis or emphysema, oral corticosteroids were used by $3.1 \%$ of daily smokers compared with $5.2 \%$ of nonsmokers (25). Therefore, we expect the confounding effect of smoking, after controlling for severity of the disease, to be limited.

The clinical implications of our results are that preventing even moderate exacerbations of COPD not necessarily leading to hospitalization may allow for a decrease in the frequency of AMI. Furthermore, when an exacerbation occurs, it coincides with an increased risk of myocardial infarction in such patients, and therefore, appropriate diagnostic and preventive strategies need to be adopted.

ACKNOWLEDGEMENTS: We thank Abbas Kezouh and Martin Senecal for database management and statistical advice. We also thank Caroline Quach and Mylene Kosseim for editorial comments.

FUNDING: This study was funded by grants from the Canadian Institutes of Health Research, AstraZeneca, Boehringer Ingelheim and GlaxoSmithKline. L Huiart was the recipient of a research fellowship, Bourse Lavoisier, from the French Foreign Affair Ministry. S Suissa was the recipient of a Distinguished Scientist award from the Canadian Institutes of Health Research. The McGill Pharmacoepidemiology Research Unit is funded by an infrastructure grant from the Fonds de la Recherche en Santé du Québec.

exacerbations of chronic obstructive pulmonary disease. Cochrane Database Syst Rev 2001:CD001288.

6. Niewoehner DE, Erbland ML, Deupree RH, et al. Effect of systemic glucocorticoids on exacerbations of chronic obstructive pulmonary disease. Department of Veterans Affairs Cooperative Study Group. N Engl J Med 1999;340:1941-7.

7. Maxwell SR, Moots RJ, Kendall MJ. Corticosteroids: Do they damage the cardiovascular system? Postgrad Med J 1994;70:863-70.

8. Sholter DE, Armstrong PW. Adverse effects of corticosteroids on the cardiovascular system. Can J Cardiol 2000;16:505-11. 
9. Becker DM, Chamberlain B, Swank R, et al. Relationship between corticosteroid exposure and plasma lipid levels in heart transplant recipients. Am J Med 1988;85:632-8.

10. Svenungsson E, Jensen-Urstad K, Heimburger M, et al. Risk factors for cardiovascular disease in systemic lupus erythematosus. Circulation 2001;104:1887-93.

11. Wallberg-Jonsson S, Ohman ML, Dahlqvist SR. Cardiovascular morbidity and mortality in patients with seropositive rheumatoid arthritis in Northern Sweden. J Rheumatol 1997;24:445-51.

12. Haider AW, Larson MG, O'Donnell CJ, Evans JC, Wilson PW, Levy D. The association of chronic cough with the risk of myocardial infarction: The Framingham Heart Study. Am J Med 1999;106:279-84.

13. Zureik M, Kauffmann F, Touboul PJ, Courbon D, Ducimetiere P. Association between peak expiratory flow and the development of carotid atherosclerotic plaques. Arch Intern Med 2001;161:1669-76.

14. Antonelli Incalzi R, Fuso L, De Rosa M, et al. Co-morbidity contributes to predict mortality of patients with chronic obstructive pulmonary disease. Eur Respir J 1997;10:2794-800.

15. Downey W, Beck P, McNutt M, et al. Health databases in Saskatchewan. In: Strom B, ed. Pharmacoepidemiology. Chicester: John Wiley \& Sons, Ltd, 2000:325-45.

16. World Health Organization. Manual of the International Statistical Classification of Diseases, Injuries and Causes of Death. Geneva: WHO, 1977

17. Rawson NS, Malcolm E. Validity of the recording of ischaemic heart disease and chronic obstructive pulmonary disease in the Saskatchewan health care datafiles. Stat Med 1995;14:2627-43.
18. Suissa S. Novel approaches to pharmacoepidemiology study design and statistical analysis. In: Strom BL, ed. Pharmacoepidemiology. New York: John Wiley \& Sons, Ltd, 2000:785-805.

19. Costa J. Corticotrophins and corticosteroids. In: Dukes M, Aronson J, eds. Meyler's Side Effects of Drugs. New York: Elsevier Science, 2000:1364-95.

20. Garbe E, LeLorier J, Boivin JF, Suissa S. Risk of ocular hypertension or open-angle glaucoma in elderly patients on oral glucocorticoids. Lancet 1997;350:979-82.

21. Hole DJ, Watt GC, Davey-Smith G, Hart CL, Gillis CR, Hawthorne VM. Impaired lung function and mortality risk in men and women: Findings from the Renfrew and Paisley prospective population study. BMJ 1996;313:711-5.

22. Anthonisen NR, Connett JE, Enright PL, Manfreda J; Lung Health Study Research Group. Hospitalizations and mortality in the Lung Health Study. Am J Respir Crit Care Med 2002;166:333-9.

23. Fuso L, Incalzi RA, Pistelli R, et al. Predicting mortality of patients hospitalized for acutely exacerbated chronic obstructive pulmonary disease. Am J Med 1995;98:272-7.

24. Yunginger JW, Reed CE, O'Connell EJ, Melton LJ III, O'Fallon WM, Silverstein MD. A community-based study of the epidemiology of asthma. Incidence rates, 1964-1983. Am Rev Respir Dis 1992;146:888-94.

25. Statistics Canada. National Population Health Survey - 1996-1997. Public use microdata files: Household component. Survey number 82M0009. Ottawa: Statistics Canada, Heath Statistics Division, 1998 


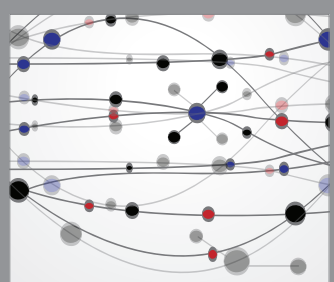

The Scientific World Journal
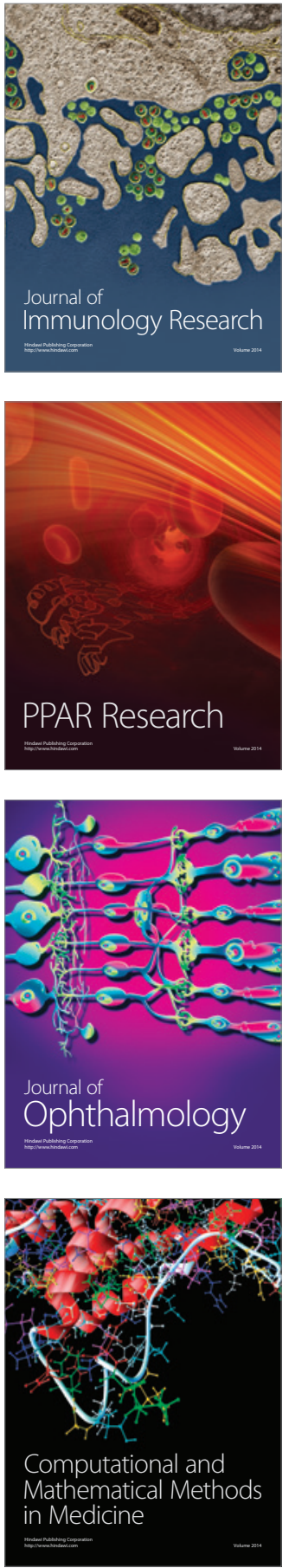

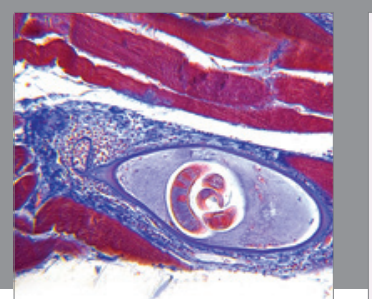

Gastroenterology Research and Practice

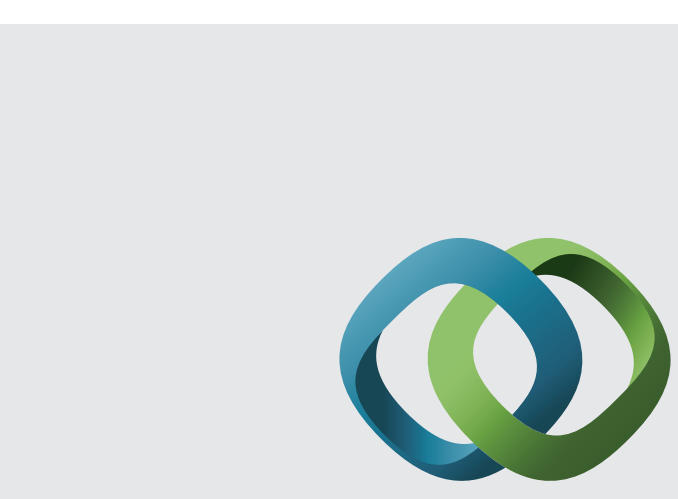

\section{Hindawi}

Submit your manuscripts at

http://www.hindawi.com
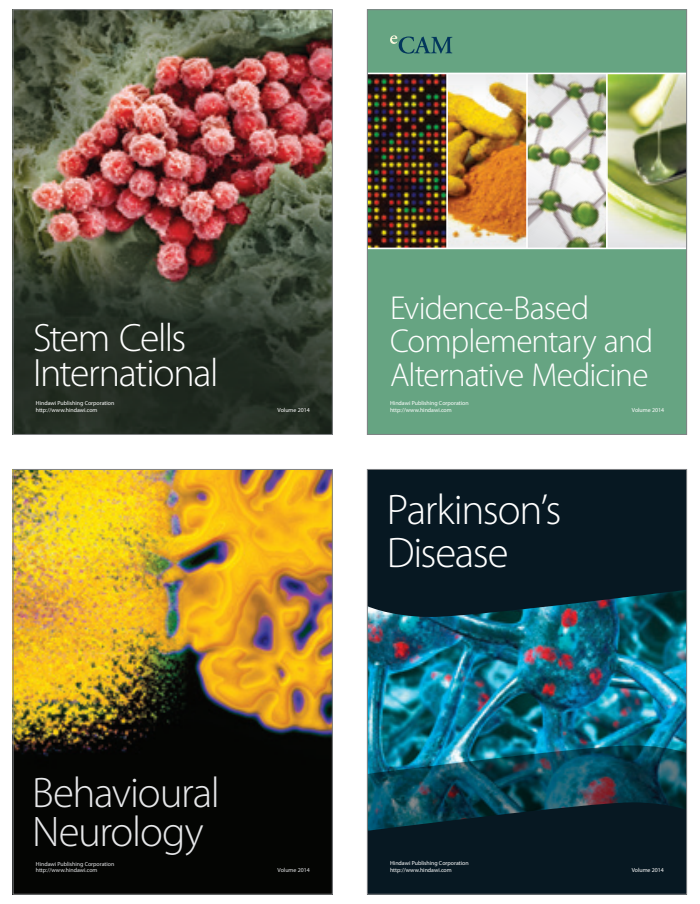
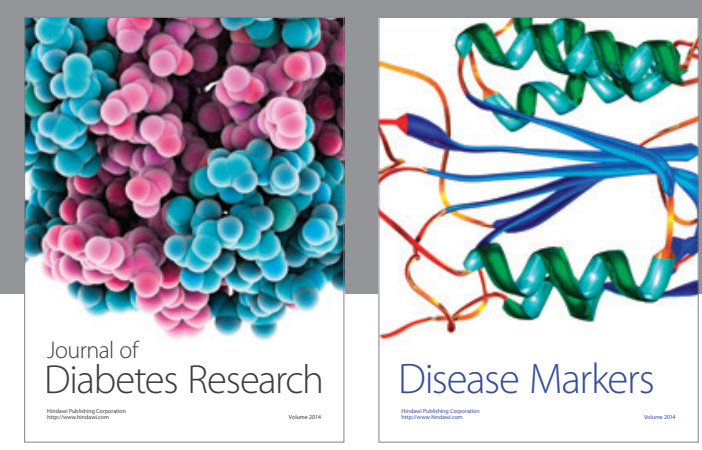

Disease Markers
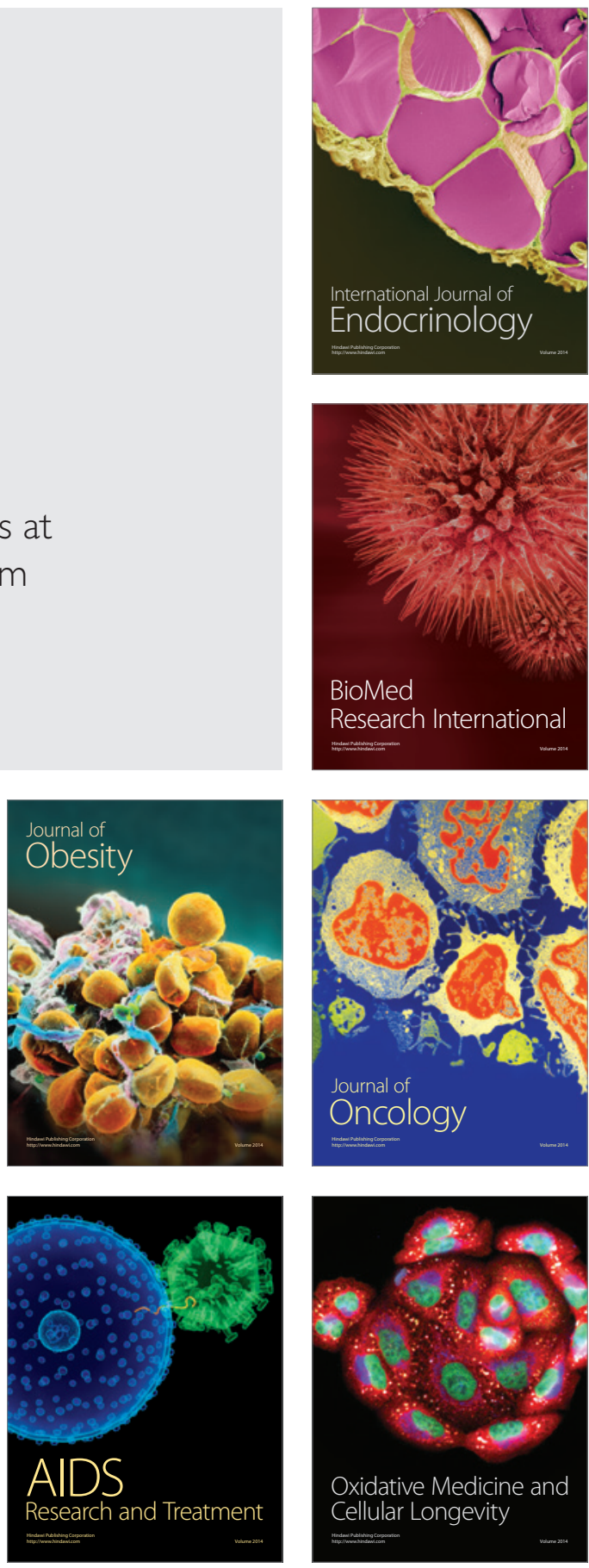